\title{
THE CURRENT SCREENING TECHNOLOGIES OF GENE EXPRESSION PROFILE IN DIABETES MELLITUS
}

\author{
HOLIFA SAHEERA ASMARA ${ }^{1}$, MAINUL HAQUE ${ }^{2 *}$
}

${ }^{1}$ Faculty of Medicine, Universiti Sultan Zainal Abidin, Terengganu, Malaysia. ${ }^{2}$ Unit of Pharmacology, Faculty of Medicine and Defence Health, Universiti Pertahanan Nasional Malaysia (National Defense University of Malaysia), Kem Sungai Besi, 57000 Kuala Lumpur, Malaysia. Email: runurono@gmail.com

Received: 01 June 2017, Revised and Accepted: 12 June 2017

ABSTRACT

Diabetes is commonly observed as a complexity and alteration of metabolic pathways through the oxidative stress and inflammations. It is a chronic condition, which has shown adverse effects and damages mechanisms. A broad study involving latest technologies has been conducted to view the alteration of gene expressions to understand the underlying of diabetes complications, a high rank of mortal disease worldwide, which demands a high cost of treatments and medications. This technology has engaged with the method of gene expression detection, which is available in the laboratory settings, includes microarray system, real-time polymerase chain reaction and next-generation sequencing. The output from gene expressions studies contributes to a better understanding of the molecular mechanism, promising a better possible gene target therapy and preventions.

Keywords: Gene expression, Microarray, Real-time polymerase chain reaction, Next-generation sequencing, Diabetes.

(C) 2017 The Authors. Published by Innovare Academic Sciences Pvt Ltd. This is an open access article under the CC BY license (http://creativecommons. org/licenses/by/4. 0/) DOI: http://dx.doi.org/10.22159/ajpcr.2017.v10i8.20420

\section{INTRODUCTION}

Diabetes mellitus (DM) is a deleterious disease involves metabolism disorders characterized by hyperglycemia resulting from defects in insulin secretion, insulin action, or both [1-5]. Globally, at this time there are over 150-382 million diabetics exists, and it is expected that the number of diabetic patients will increase due to a sedentary lifestyle, consumption of energy rich diet and obesity [6-8]. Again, good portion of diabetic patients is not aware that they are diabetic and much more are prediabetic even in modern countries $[9,10]$. Nevertheless, it was often observed that the diabetic patients' perceptions of about their health not related to the clinical consequences. Diabetic patient management needs alteration of lifestyles and behaviors to optimize the quality of life and wellbeing $[11,12]$. The capability of a person has been reduced by the DM to normalize the level of glucose in the blood that results in many impediments that can either be minor or major. In the majority of the cases, the DM can be categorized into two most important etiopathogenetic classes. Type 1 diabetes mellitus (T1DM) is a congenital condition in which the organ which releases the insulin is malfunctioned or damaged by default [13]. T1DM generally occurs in the people who are $<35$ years of age, mostly in youth and early middle age. It is basically an autoimmune disorder that occurs due to the damage of $\beta$-cells through stimulated $\mathrm{CD}^{+}$and $\mathrm{CD}^{+}$cells in the islets of the pancreas. This type of diabetes is called as neonatal diabetes that is diagnosable and can either be temporary or everlasting. While type 2 diabetes mellitus (T2DM) is mainly characterized by insulin resistance (IR) [14]. T2DM is observed in obesity, high cholesterol diet and sedentary lifestyle [14]. The T2DM is diagnosable in almost the fourth decade of the age and most of the people around the world have T2DM, by giving $90 \%$ of the world population has this chronic T2DM. Chronic T2DM is significantly associated with metabolic syndrome (MS) [15] which is characterized by other criteria; hypertension, dyslipidemia, and central obesity $[15,16]$. Clinically, diabetic patients normally are asymptomatic in an early stage, and then complications will arise subsequently [17]. A common complication of diabetes includes neuropathy, retinopathy, renal failure, and cardiovascular diseases [18], and diabetic encephalopathy [18]. It also includes neuropathy with high risk of foot ulcers. Chronic diabetes shows a high oxidative stress status and inflammation state [19]. Statistically, diabetes is among the major diseases reported worldwide and is considered as a burden to the health-care system due to its incurable disease where the patients are treated based on its symptoms and its complications $[15,16]$. Thus, the cost of treatments on complications of diabetes is increasing with the increased cases reported in the present. Wisely, if the disease could be treated or prevented in the early stage it may reduce the burden of health care department's cost worldwide on the medications and treatments [20]. Recent technology of diseases detection is using mRNA expression screening, which has been widely used. The data interpretation shows the abnormal regulation of gene expression, which accurately explains the mechanism of pathogenesis of disease and the associated diseases. The abnormalities of gene expression could be corrected by reversing the pathways molecularly.

\section{MRNA EXPRESSION AND METABOLIC DISORDERS}

Messenger ribonucleic acid (mRNA) is a sequence of nucleotides and template to deoxyribonucleic acid (DNA) involve in the genetic replication process. It is a family of ribonucleic acid (RNA) molecules that arranged into codons consisting of three base pairs each, which deliver the genetic information from DNA to the ribosome to design the amino acids sequence in proteins products of gene expression, specifically. This is how the genetic code is kept to ensure the information is identical to the parental chromosomes. Stability of mRNA in a different organism is distinct, compare to prokaryotes; mammalian cells have mRNA lifetime range from minutes to days, which they survive for seconds to hours.

The mRNA action in metabolic disorders has been recognized [20] and has a significant impact in many studies scientifically. The screening of mRNA expression has been studied widely in metabolic disorders [21] in understanding the underlying mechanism. Metabolic disorders are often affected by alteration of gene expression [22] and metabolic pathways [23]. Various metabolic disorders have been recorded till present, major classification of metabolic disorders involves the alteration of metabolic pathways. Among the disorders, MS is frequently discussed recently [24] and 
becomes a new trend of metabolism abnormalities, the risk factors of obesity and T2DM [1]. A study in subjects with MS and earlyonset coronary artery disease revealed that heterozygous missense mutation in the DYRK1B gene (R102C; 604556.0001) was detected through whole exome sequencing in the probands [13]. Coronary heart disease significantly associated with MS. Hyperlipidemia is one of the criteria of MS featured by high plasma low-density lipoproteincholesterol [5].

A significant relationship between obesity and T2DM has been recorded, in both within and among different populations [25]. Obesity commonly remarks as hyperlipidemia and hypercholesterolemia [26]; hypertriglyceridemia precedes the onset of hyperglycemia [27]. Downregulated of adipogenic genes such as transcription factor adipocyte determination factor 1 /sterol regulatory element binding protein was observed in adipocytes and correlated with mild hyperglycemia in obese and insulin resistant in lean. Contrarily, SREBP1 and lipogenic target genes were upregulated indicating increased in fatty acid biosynthesis that leads to increasing fatty acid production from the liver. Other than that, a study has proposed eight candidates gene for obesity; BAP1, GRB14, HSP90AB1, ITGA5, NCKAP5L, SP1, and TOMM5; closely related with $P R K C B$ and $L Y N$, the candidate genes of T2DM [28].

\section{GENE EXPRESSION IN T2DM}

T2DM has become a global disease and burden and has increased rapidly [29]. It is a complex endocrine and metabolic disorder with various of complications rises, characterized by IR and deficient $\beta$-cell function [28]. The pathogenesis of the disease is suggested to be affected by the intercommunication of multiple genetics and risk factors. A complicated metabolic disorder such as diabetes is affected by broad gene expression in numerous tissues. A recent study has reported that six candidate genes were found significantly high in the T2DM study; ENND1B, LYN, MRPL30, POC1B, PRKCB, and RP4$655 J 12.3$ [28]. PRKCB is observed to be upregulated in skeletal muscle, islets, adipose tissue, and blood, and downregulated in the liver of T2DM subject, suggested to involve in IR and decreased $\beta$-cell function. $P R K C B$ is mainly associated with T2DM; PRKCB and GRB14 are involved in insulin signaling within the gene pathway network. $P R K C B$ mediates $\mathrm{Ca}^{2+}$ and DAG-evoked insulin secretion processes. However, $L Y N$ is implicated in the insulin signaling pathway via phosphorylation of insulin receptor substrate-1 (IRS-1) and PI3K in liver and adipose tissues [28].

\section{DETECTION OF GENE EXPRESSION AND TECHNOLOGIES}

\section{Technologies for gene identification}

mRNA expression profiles have been utilized to classify and diagnose the disease. The mRNA can be extracted from various sample types such as blood, plasma, serum, fresh frozen tissue, formalin fixed paraffin embedded tissue, or cell lines for the purpose of identifying distinct mRNA signature. Most of the analysis results of mRNA expression using different platforms have shown good reproducibility. However, the differences in the expression of mRNAs level observed between platforms suggest there may be factors contributing to these discrepancies data are (1) different methodologies used to extract total RNA as a starting material for the analysis and (2) different types of samples used in the expression analysis [24].

\section{Northern blot analysis}

It is utilized to detect and identify gene expression at the mRNA or miRNA level. However, the assay is less sensitive in detecting low abundant miRNA especially with a limited source of tissue or cells. Therefore, a new modified technology has improved the sensitivity and specificity to detect miRNA using locked nucleic acid (LNA)modified oligonucleotide probes. This technique has been applied worldwide for mRNA and protein expressions to understand in-depth mechanisms involving chronic disease such as diabetes [30-32]. Sprague Dawley rats was used as an animal model in the study utilizing this technique to identify the expression of mRNA. The study focuses on one of the diabetes complication like diabetic nephropathy. They found that the transforming growth factor $\beta$ (TGF- $\beta$ ) mRNA and TGF- $\beta$ protein were upregulated, which TGF- $\beta$ induces the production of extracellular matrix. In the diabetic rat, TGF- $\beta$ stimulates a specific matrix proteins production to include a selectively joined form of fibronectin, tenascin, and the proteoglycan biglycan, that were increased in glomeruli [30]. Recently, a research work has used this technique to detect the expression of gene and proteins to study the molecular relationship of obesity and diabetes in rat or mice. The study found that certain gene and proteins expression level were altered, thereafter, these conditions are related with each other. Obesity causes stress in endoplasmic reticulum precedes insulin receptor signaling suppression through the hyperactivation of the c-Jun N-terminal kinase (JNK) leads to serine phosphorylation of IRS-1 [32].

\section{Microarray technology}

This technique uses the concept of hybridization for a complementary stranded nucleic acid in which the DNA (template) on the glass slide is hybridized with labeled probes with the fluorescent dye. Thus, the technology is considered high sensitive and specific in identifying large-scale gene expression. The issues which were considered as the non-traceable issues in the field of genetics by the researchers are now can be investigated and addressed by them through a technology called DNA microarray. mRNA microarray analysis is a high-throughput technique which is widely used nowadays. It is used to investigate expression levels of hundred or thousand mRNA in a large number of samples. Most common published studies reporting mRNA profiling results were carried out using various microarray technologies. This technology was developed to overcome the limitations of using northern blot analysis. Many expressions of genes can be analyzed and examined by a distinct reaction in a very well efficient way. The technology of DNA microarray has enabled the community of science to comprehend the basic facts emphasizing the enlargement and advancement of life in addition to the exploration of the genetic origins that occurs in the working the human body. The microarray experiment typically entails the hybridization of an mRNA molecule to the DNA template from which it is made; several DNA samples were used in the process of making an array. The level of expression in an assortment of genes is indicated by the quantity of mRNA which is bound to each on the array. miRNA microarray provides a useful tool to identify the miRNAs that are up- or downregulated from the tissue of interest. However, these data should be viewed as a guide and should be confirmed by other detection methods [33]. Microarraybased technologies enable several analyses such as genomewide associations, mutational analysis, drug discovery, and other molecular analyses. The microarray is basically an uncomplicated assortment of autonomously achieved dot blots for a number of genes. Several expression genes are compared in a number of ways that propose a contributory reliance. Furthermore, the expression changes comparative profusions contained by particular samples give significant information about the complicated pathways and cellular methods that are changed in a specific disease or situation. The hybridization kinetics of mRNA is not only swift and proficient but also similar to the free solution hybridization and this kinetics guarantees insignificant loss of samples. There are several kinds of arrays and chips that are commercially accessible and entail numerous quantities of mRNA. This type of advancement can be utilized to practice the quantity of mRNA essential for any kind of microarrays or macroarrays. There are a number of examples related to this approach, for instance, segregation of mRNA for GeneChips arrays or chips, also for microarray expressions of genes and other several kinds of arrays [33,34]. A study was using the microrrarray method combining with congenic mapping to study the expression of the protein and find the relationship between genotype and phenotype of diabetic mice. Another study [36] also using microarray to study the gene expression in diabetes using analytical strategy. This study specifically involves a set of gene activated by PGC1- $\alpha$ via 
oxidative phosphorylation which is related to the capacity of total body aerobic were found to be downregulated systematically [36]. Recently, this method is still being used in other research works particularly to develop the gene profiling and gene expression related to diabetes. A study was using this technique to explain the cellular signaling pathways in T2DM, found a signature set of new drug target genes of the disease [37]. A number of studies [35-37] using this method to elucidate the molecular mechanism of diabetes, giving a better understanding how to treat diabetes at molecular level reducing their progressions and complications resulted from irregular of gene expression level altered by the disease.

\section{Next-generation sequencing}

Recently, NGS platforms such as Illumina HiSeq 2005, NanoString nCounter analysis system and Illumina/Solexa Genome Analyzer sequencing, or Roche 454 Genome Sequencer FLX became available for the sequencing of RNA molecules. A study reported using NanoString nCounter system to characterize the gene expression in a patient within insulin resistant in respond to fish oil (omega-3) [38]. Other study had been reported using Illumina HiSeq 2005, Prabhakar, S.S. and colleagues to characterize the RNA expression of the kidney from diabetic rat [30]. Several studies had been reported using Illumina/Solexa Genome Analyzer, for example, Ramsingh and colleagues used 454-based sequencing to characterize the microRNAome in a patient with acute myeloid leukemia [39]. To the best of our knowledge, currently, there are only a few published data on gene expression profiling in T2DM using DNA or RNA sequencing technologies [40-42] in mRNA expression study. Unlike microarray platforms, deep or large-scale parallel sequencing methods facilitates the genome-wide transcriptase analysis in identifying novel or unknown transcripts. This technology provides a huge data that needs bioinformatics to analyze the data. Many of the software are available to help users with the analysis of data [43]. The advantage of using this technology is that it can concurrently facilitate multiple gene analysis in a single run $[43,44]$. A study has used this technique and successfully developed a highly sensitive targeted next-generation sequencing assay to detect mutations in all known MODY (maturity onset diabetes of the young) and neonatal diabetes genes, rather than existing genetic test that count on the selection of target gene based on patient's phenotype [44]. NGS was enabled to detect the mutation of ABCC8 mutation in whole exome sequencing (WES) in nonautoimmune neonatal diabetes patient, which expected to carrying a mutation in KCJN11 and ABCC8 in a single analysis [45], compare to the conventional method for gene detection [43-45]. This is a very critical issue since these particular mutations could be handled by oral sulfonylurea drugs rather than insulin injection [45]. Therefore, NGS is strongly suggested to be the future reliable, comprehensive and inexpensive technique for to diagnosis multiple types of diabetes according to a targeted mutation of the gene for better patient managements [43-45].

\section{Quantitative real-time polymerase chain reaction (qRT-PCR)}

It is a technique to quantify the level of gene expression in diseases of certain known genes. The advantage of this technique compared to Northern blotting and microarray is that this technique provides both sensitivity and specificity. Because it only requires a single nucleotide and small quantity of total RNA, it allows the specific identifying of individual miRNA family members. Furthermore, it is widely used as a validation method for targeted mRNA after mRNAs microarray expression analysis. Nowadays, qRT-PCR focus panels for mRNA studies are available, for example, diabetes or cancer focuses panels and plasma or serum focus panel. This ready to use PCR panels enable fast and easy mRNA expression profiling as well as sensitive and accurate detection of mRNA [46,47]. In diabetes study, this technique has been used widely to identify the specific gene expression. In about a decade ago a study was conducted to investigate the effect of exercise training and calorie restriction on the expression of the SRBP-1 gene in obesity. The study concluded that, in interventions,
SREBP-1 protein and SREBP-1c mRNA were elevated thus enhancing IMTG with increased insulin sensitivity. Interventions-induced elevation of SREBP-1 expression seen in skeletal muscle of athletes might be the primary causes for the upregulated IMTG [48]. Another study recently was using the qRT-PCR technique to investigate the expression of antioxidants and detoxification genes. This technique is used to validate the microarray results on the effect of resveratrol on streptozotocin-induced diabetic rat to prove distinctively the transcription regulation networks expressed, with the suggestion that resveratrol supplementation can be used to reverse the progressive of diabetes [49].

\section{In situ hybridization (ISH)}

Specific nuclei acid sequences in tissue samples can be detected using ISH in which the technology enables to detect the gene expression at the cellular level in cell populations and elucidate the role of miRNAs in molecular and biological processes. The accumulation of gene expression in their basic or natural medium is indicated by ISH. Surrounded by a sample, a marked DNA or RNA investigation can be utilized to hybridize to an acknowledged intention of DNA or mRNA sequence. This marked DNA or RNA investigation can then be identified by utilizing an antibody to distinguish the label on the probe. This probe is then utilized to identify the gene expression and the position of mRNA. There are many advantages of ISH that includes the rapidity in which the particular investigations for ISH can be originated from the sections of acknowledged sequence of DNA and that can be compared to the practices of immunological. The target sequence is identified in tissues directly with the usage of ISH [50]. In a recent study, this method has been used to quantify the level of BiP mRNA expression in the supraoptic nucleus and paraventricular nucleus of hypothalamus by integrated optimal densities measurements from the film images. In this study, arginine vasopressin (AVP) intronic probe for hnRNA was created from a 685bp fragment holding bases 171-855 of the mouse AVP intron 1. The BiP exonic probe was constituted from a 922-bp fragment containing bases 852-1773 of BiP cDNA. Antisense probes of AVP hnRNA and BiP mRNA which were highly specific, synthesized using $55 \mu \mathrm{Ci}$ [35S] UTP and $171 \mu \mathrm{Ci}$ [35S] CTP, 15 units of RNasin, $1 \mu \mathrm{g}$ of the linearized template, and 15 units of SP6 RNA polymerase. The study concluded that the expression levels of BiP mRNA between familial neurohypophyseal diabetes insipidus (FNDI) and wild-type mice were similar thus; ER-associated compartment development relieves ER stress that resulted from the mutant proteins abundance in AVP neurons of FNDI mice [51].

\section{Future expectation}

The potential value of using mRNAs as biomarkers in diabetes has been shown by numerous promising data. Despite strong evidence supporting the potential value of mRNAs as biomarkers, several issues need to be addressed to ensure the results obtained are consistent. As for example, inconsistencies in results obtained from the various platform of technology will provide the limitation in unraveling the molecular and biological function of mRNA in diabetes. Detection and quantification of mRNA expression should be robust, rapid, accurate, reproducible, and inexpensive. This is significantly important to make sure accurate results can be obtained. The discovery of mRNAs as potential diagnostic and prognostic biomarkers will open a new era in the management of diabetes.

\section{REFERENCES}

1. Barbieri M. Cognitive decline and diabetes: A focus on linking mechanisms. Part II: General aspect nutritional factors and specific conditions in dementia and cognitive decline. In: Diet and Nutrition in Dementia and Cognitive Decline. Ch. 35. Broomfield, CO, US: Elsevier Inc.; 2015. p. 393-2.

2. Alwin C. Powers diabetes mellitus. In: Longo DL, Fauci AS, Kasper DL, Hauser SL, Jameson JL, Loscalzo J, editors. Harrison's Principles of Internal Medicine. $18^{\text {th }}$ ed. New York: McGraw-Hill 
Medical Publishing Division; 2008. p. 2968-9.

3. Mushtaq S, Mayee KR, Amreen S, Satyanarayana V, Yerramilli A, Ramakrishnana S. A study on the current prescribing patterns of dipeptidyl peptidase 4 inhibitors in a multi speciality hospital outpatient setting. Asian J Pharm Clin Res 2014;7 Suppl 2:134-6.

4. Islam MA, Akhtar MA, Khan MR, Hossain MS, Alam AH, Wahed MI, et al. Oral glucose tolerance test (OGTT) in normal control and glucose induced hyperglycemia rats with Coccinia cordifolia L. and Catharanthus roseus L. Pak J Pharm 2009;22(4):402-4.

5. Toth C. Diabetes and neurodegeneration in the brain. In: Zochodne DW, Malik RA, editors. Handbook of Clinical Neurology. $1^{\text {st }}$ ed. Ch. 32. New York, NY: Elsevier B.V.; 2014. p. 489-11.

6. Malini P, Kanchana G, Rajadurai M. Antibiabetic efficacy of ellagic acid in streptozotocininduced diabetes mellitus in albino wistar rats. Asian J Pharm Clin Res 2011;4(3):1248.

7. Stalin C, Dineshkumar P, Nithiyananthan K. Evaluation of antidiabetic activity of methanolic leaf extract of ficus Carica in alloxan-induced diabetic rats. Asian J Pharm Clin Res 2012;5(3):85-7.

8. Moradi M, Mousavi S. Drug use evaluation of diabetes mellitus in nonhospitalized patients. Int J Pharm Pharm Sci 2016;8:337-41.

9. Guariguata L, Whiting DR, Hambleton I, Beagley J, Linnenkamp U, Shaw JE. Global estimates of diabetes prevalence for 2013 and projections for 2035. Diabetes Res Clin Pract 2014;103(2):137-49.

10. Ibrahim R. Diabetes mellitus Type II: Review of oral treatment options. Int J Pharm Pharm Sci 2010;2:21.

11. Andayani TM, Ibrahim MI, Asdie AH. The association of diabetesrelated factor and quality of life in Type 2 diabetes mellitus. Int J Pharm Pharm Sci 2010;2:139-45.

12. Huang IC, Liu JH, Wu AW, Wu MY, Leite W, Hwang CC. Evaluating the reliability, validity and minimally important difference of the Taiwanese version of the diabetes quality of life (DQOL) measurement. Health Qual Life Outcomes 2008;6:87.

13. Sickmann HM, Waagepetersen HS, Schousboe A, Benie AJ, Bouman SD. Obesity and Type 2 diabetes in rats are associated with altered brain glycogen and amino-acid homeostasis. J Cereb Blood Flow Metab 2010;30(8):1527-37

14. Buettner R, Parhofer KG, Woenckhaus M, Wrede CE, Kunz-Schughart LA, Schölmerich J, et al. Defining high-fat-diet rat models: Metabolic and molecular effects of different fat types. J Mol Endocrinol 2006;36(3):485-501

15. Saumet A, Vetter G, Bouttier M, Portales-Casamar E, Wasserman WW, Maurin T, et al. Transcriptional repression of microRNA genes by PML-RARA increases expression of key cancer proteins in acute promyelocytic leukemia. Blood J 2017;113(2):412-22.

16. Aboonabi A, Rahmat A, Othman F. Antioxidant effect of promegranate against streptozotocin-nicotinamide generatedcoxidative stress induced diabetic rats. Toxicol Rep 2014;1:915-22.

17. American Diabetes Association. Diagnosis and classification of diabetes mellitus. Diabetes Care 2009;32:S62-7.

18. Budin SB, Othman F, Louis SR, Bakar MA, Das S, Mohamed J. The effects of palm oil tocotrienol-rich fraction supplementation on biochemical parameters, oxidative stress and the vascular wall of streptozotocin-induced diabetic rats. Clinics (Sao Paulo) 2009;64(3):235-44.

19. Biessels GJ, Gispen WH. The impact of diabetes on cognition: What can be learned from rodent models? Neurobiol Aging 2005;26 Suppl 1:36-41.

20. Chen CZ. MicroRNAs as oncogenes and tumor suppressors. N Engl J Med 2005;353:1768-71

21. Kuhad A, Chopra K. Attenuation of diabetic nephropathy by tocotrienol: Involvement of NFkB signaling pathway. Life Sci 2009;84(910):296-301.

22. Lê KA, Faeh D, Stettler R, Debard C, Loizon E, Vidal H, et al. Effects of four-week high-fructose diet on gene expression in skeletal muscle of healthy men. Diabetes Metab 2008;34(1):82-5.

23. Ajamian F, Titok T, Suhorada E, Ruban T, Reeben M. Hepatic expression of the human insulin gene reduces glucose levels. Prelim Rep 2003;1627:424-9.

24. Nurul-Syakima AM, Yoke-Kqueen C, Sabariah AR, Shiran MS, Singh A, Learn-Han L. Differential microRNA expression and identification of putative miRNA targets and pathways in head and neck cancers. Int J Mol Med 2011;28(3):327-36.

25. Saito Y, Liang G, Egger G, Friedman JM, Chuang JC, Coetzee GA, et al. Specific activation of microRNA-127 with downregulation of the proto-oncogene BCL6 by chromatin-modifying drugs in human cancer cells. Cancer Cell 2006;9:435-43.

26. Takamizawa J, Konishi H, Yanagisawa K, Tomida S, Osada H, Endoh H, et al. Advances in brief reduced expression of the let-7 microRNAs in human lung cancers in association with shortened postoperative survival. Cancer Res 2004;64:3753-6.

27. Weber M, Baker MB, Patel RS, Quyyumi AA, Bao G, Searles CD. MicroRNA expression profile in CAD patients and the impact of ACEI/ ARB. Cardiol Res Pract 2011;2011:532915.

28. Wu W, Yang J, Feng X, Wang H, Ye S, Yang, et al. MicroRNA-32 (miR-32) regulates phosphatase and tensin homologue (PTEN) expression and promotes growth, migration and invasion in colorectal carcinoma cells. Mol Cancer 2013;30:1-11.

29. Liang RQ, Li W, Li Y, Tan CY, Li JX, Jin YX, et al. An oligonucleotide microarray for microRNA expression analysis based on labeling RNA with quantum dot and nanogold probe. Nucleic Acids Res 2005;33(2): 17 .

30. Yamamoto T, Nakamura T, Noble NA, Ruoslahti E, Border WA. Expression of transforming growth factor beta is elevated in human and experimental diabetic nephropathy. Proc Natl Acad Sci U S A 1993;90(5):1814-8.

31. Lee YS, Kim WS, Kim KH, Yoon MJ, Cho HJ, Shen Y, et al. Berberine, a natural plant product, activates AMP-activated protein kinase with beneficial metabolic effects in diabetic and insulin-resistant states. Diabetes 2006;55:2256-64.

32. Ozcan U, Cao Q, Yilmaz E, Lee AH, Iwakoshi NN, Ozdelen E, et al. Endoplasmic reticulum stress links obesity, insulin action, and Type 2 diabetes. Science 2004;306(5695):457-61.

33. van Rooij E. The art of microRNA research. Circ Res 2011;108(2):219-34.

34. Git A, Dvinge H, Osborne M, Kutter C, Hadfield J, Bertone P, et al. Systematic comparison of microarray profiling, real-time PCR and next-generation sequencing technologies for measuring differential microRNA expression. RNA 2010;16:991-6.

35. Eaves IA, Wicker LS, Ghandour G, Lyons PA, Peterson LB, Todd JA, et al. Combining mouse congenic strains and microarray gene expression analyses to study a complex trait: The NOD model of Type 1 diabetes. Genome Res 2003;12:232-3.

36. Mootha VK, Lindgren CM, Eriksson KF, Subramanian A, Sihag S, Lehar J, et al. PGC-1-alpha-responsive genes involved in oxidative phosphorylation are coordinately downregulated in human diabetes. Nat Gen 2003;34:267-73.

37. Muhammad SA, Raza W, Nguyen T, Bai B, Wu X, Chen J. Cellular signaling pathways in insulin resistance-systems biology analyses of microarray dataset reveals new drug target gene signatures of Type 2 diabetes mellitus. Front Physiol 2017;8(1):1-15

38. Spencer M, Finlin BS, Unal R, Zhu B, Morris AJ, Shipp LR, et al. Omega-3 fatty acids reduce adipose tissue macrophages in human subjects with insulin resistance. Diabetes 2013;62(5):1709-17.

39. Ramsingh G, Koboldt DC, Trissal M, Chiappinelli KB, Wylie T, Koul S, et al. Complete characterization of the microRNAome in a patient with acute myeloid leukemia. Blood 2010;116(24):5316-26.

40. Statnick MA, Beavers LS, Conner LJ, Corominola H, Johnson D, Hammond CD, et al. Decreased expression of apM1 in omental and subcutaneous adipose tissue of humans with Type 2 diabetes. Int J Exp Diabetes Res 1999;1:81-8.

41. Napoli Z, Seghieri G, Bianchi L, Anichini R, de Bellis A, Campesi I, et al. Taurine transporter gene expression in mononuclear blood cells of Type 1 diabetes patients. J Diabetes Res 2016;2016:1-7.

42. Wu X, Xu H, Zhang Z, Chang Q, Liao S, Zhang L, et al. Transcriptome profiles using next-generation sequencing reveal liver changes in the early stage of diabetes in tree shrew (Tupaia belangeri chinensis). J Diabetes Res 2016;2016:1-15.

43. Metzker ML. Sequencing technologies-the next generation. Nat Rev Genet 2010;11:31-6.

44. Ellard S, Lango Allen H, De Franco E, Flanagan SE, Hysenaj G, Colclough $\mathrm{K}$, et al. Improved genetic testing for monogenic diabetes using targeted next-generation sequencing. Diabetologia 2013;56(9):1958-63.

45. Bonnefond A, Durand E, Sand O, de Graeve F, Gallina S, Busiah $\mathrm{K}$, et al. Molecular diagnosis of neonatal diabetes mellitus using next-generation sequencing of the whole exome. PLoS One 2010;5:e13630

46. Heid CA, Stevens J, Livak KJ, Williams PM. Real time quantitative PCR. Genome Res 1996;6(10):986-94.

47. Chen C, Ridzon DA, Broomer AJ, Zhou Z, Lee DH, Nguyen JT, et al. Real-time quantification of microRNAs by stem-loop RT-PCR. Nucleic Acids Res 2005;33(20):e179.

48. Nadeau KJ, Ehlers LB, Aguirre LE, Moore RL, Jew KN, Ortmeyer HK, et al. Exercise training and calorie restriction increase SREBP-1 
expression and intramuscular triglyceride in skeletal muscle. Am J Physiol Endocrinol Metab 2006;291:90-8.

49. Sadi G, Baloglu MC, Pektas MB. Differential gene expression in liver tissues of streptozotocin-induced diabetic rats in response to resveratrol treatment. PLoS One 2015;10(4):e0124968.

50. Kloosterman WP, Wienholds E, de Bruijn E, Kauppinen S, Plasterk RH.
In situ detection of miRNAs in animal embryos using LNA-modified oligonucleotide probes. Nat Methods 2006;3(1):27-9.

51. Hagiwara D, Arima H, Morishita Y, Wenjun L, Azuma Y, Ito Y, et al. Arginine vasopressin neuronal loss results from autophagy-associated cell death in a mouse model for familial neurohypophysial diabetes insipidus. Cell Death Dis 2014;5(3):e1148-9. 